\title{
Article \\ Relationship between Physical Environment Satisfaction, Neighborhood Satisfaction, and Quality of Life in Gyeonggi, Korea
}

\author{
Kyung-Young Lee (D)
}

check for updates

Citation: Lee, K.-Y. Relationship between Physical Environment Satisfaction, Neighborhood Satisfaction, and Quality of Life in Gyeonggi, Korea. Land 2021, 10, 663. https://doi.org/10.3390/land10070663

Academic Editor:

Anna Winiarczyk-Raźniak

Received: 8 June 2021

Accepted: 15 June 2021

Published: 23 June 2021

Publisher's Note: MDPI stays neutral with regard to jurisdictional claims in published maps and institutional affiliations.

Copyright: (C) 2021 by the author. Licensee MDPI, Basel, Switzerland. This article is an open access article distributed under the terms and conditions of the Creative Commons Attribution (CC BY) license (https:/ / creativecommons.org/licenses/by/ $4.0 /)$.
Senior Researcher, Sustainable Urban Development Institute (SUDI), Sungkyunkwan University, Seoul 03063, Korea; kylee0501@skku.edu

\begin{abstract}
This study examined the relationship between physical environment satisfaction, neighborhood satisfaction, and quality of life (QoL) in Gyeonggi, Korea. As previous QoL studies have rarely dealt with residential environments or examined the interactions between the physical and social factors in residential environments, to close these knowledge gaps, this study took physical and social environment satisfaction factors as relevant influences on QoL. This study also verified the moderating effect of neighborhood satisfaction on QoL through physical environment satisfaction. This study analyzed a Quality of Life Survey that was conducted in Gyeonggi, Korea. The total number of samples in the survey was 20,000, covering all 31 districts in Gyeonggi Province. In addition, multistage stratified sampling based on the number of household members and housing types was applied to the sample design. This increases the representation of the data. As a result, it was found that higher satisfaction with the physical and neighborhood factors positively affected QoL, with satisfaction with the facilities having the most obvious effect. Neighborhood satisfaction was found to have a moderating effect between safety satisfaction and QoL. Many developing countries have tended to pursue quantitative growth with a focus on economic aspects, which has undermined overall urban sustainability. However, recent urban management has also emphasized qualitative growth, such as resident QoL, as being just as important for urban sustainability. Therefore, this study's results have important policy implications for qualitative urban growth.
\end{abstract}

Keywords: quality of life; physical environment satisfaction; neighborhood satisfaction; moderating effect; Gyeonggi

\section{Introduction}

Urban development is understood to encompass both quantity and quality, with an increase in population or economic size referring to the former, and an increase in quality of life (QoL) and the local environment referring to the latter. Therefore, a desirable city or urban environment is created when both quality and quantity are balanced. However, as urban management in the industrialization era has tended to prioritize quantitative growth over qualitative growth [1,2], many cities today have had remarkable quantity results compared to the past but are facing several qualitative issues, such as a decreasing QoL and resident indifference to local issues. The subjective QoL for Koreans was reported to be quite low in the "Better Life Index 2020" released by the Organization for Economic Co-operation and Development (OECD), which ranked Korea at 29th out of 35 countries. Among the surveyed countries, Australia had the highest score of 8.4 points (10-point scale), and the OECD average was 6.02. Korea scored 4.69 points. Japan in the same region ranked 25th with 5.35 points. Specifically, Korea ranked low in the indicators of "community" (35th), "work-life balance" (34th), and "life satisfaction" (29th) [3]. This means that Korean QoL is comparatively poor and efforts are urgently needed to improve it.

QoL has been defined differently, often in conjunction with notions of "happiness" and "well-being". However, QoL implies overall subjective life satisfaction [4-7]. Quality 
of life (QoL) has been a major topic in global circles. Since the mid-1970s, there has been continuing research interest in QoL issues, with the focus in developed countries being more on the "values" related to human life than on economic growth [8,9]. These discussions also influenced the paradigm of urban management. For example, there has been a significant increase in studies of good cities, safe cities, and social cities related to urban qualitative development. These studies focused on meeting the requirements for improving QoL and stressed the importance of non-visible factors such as "participation", "social bonding", and "governance" [10,11]. Korea's economic growth rate has been slowing since the mid1980s and quantitative growth and urban development expansion have begun to decline. Therefore, emphasis is being placed on qualitative development such as improvements in the "QoL" [5,7,12].

According to previous studies, various factors can affect QoL; however, most studies have been focused on economic factors [13-15], arguing that increased income levels or having a high social status (e.g., doctors, professors, and lawyers) in employment had a positive impact on QoL. Similarly, Korean studies on QoL explained that economic factors were important for quality of life. For example, the higher the income is, the higher the quality of life is [16]. It has also been proven that homeowners have a higher QoL than renters do [17]. However, in addition to economic factors, the residential environments that residents encounter everyday have also been found to significantly affect QoL $[18,19]$. Specifically, most people primarily satisfy their needs and interests within their immediate residential areas [20-22]; thus, it could be surmised that residential environments also impact QoL. As the "Urban Regeneration Projects" being implemented in major Korean cities are intended to increase QoL by improving residential environments [23], there is a need for studies on the specific influences residential environments have on QoL.

Residential environments are directly related to the environmental conditions in the places where people live [19] and comprise various elements [24-26], each of which could give rise to various resident responses. This study considered international standards for residential environments. First, the OECD emphasizes that social factors are important in assessing the quality of residential environments in addition to physical factors [5]. Furthermore, social connections and civic engagement were presented as specific items of social factors. Additionally, the World Health Organization (WHO) mentioned safety, health, convenience, and amenity as the most basic residential requirements for human beings [27]. Based on this, this study considered both physical and social attributes. Specifically, the physical elements included facilities, commuting, and safety by applying the WHO's criteria. Facilities and commuting factors are highly relevant to convenience and amenity. The social factor was constructed by neighborhood satisfaction based on the OECD discussion.

These two factors are highly related. For example, residents are generally more satisfied with the safety in their residential area if they have good neighborhood relations, which, in turn, positively affects their QoL [28]. Therefore, the physical factor's influence on QoL depends on the level of satisfaction with the neighborhood, which suggests that social factors may have a moderating effect between the physical environment and QoL. However, there has been insufficient research to confirm the interactions between the physical and social factors in residential environments.

In order to clarify this association in an urban Korean context, this study focused on two main research questions: How do residential environments affect quality of life, and do the social factors in residential environments moderate the relationship between the physical factors and quality of life?

Facilities, commuting, and safety have been identified as sub-components of physical factors, and neighborhood satisfaction has been identified as the primary social factor. Baron and Kenny's [29] moderating effect analysis was employed to examine these research questions and the associated hypotheses.

This study makes the following contributions. Firstly, it verifies the importance of the physical residential environment sub-component that affects residents' QoL, which 
provides a theoretical rationale for the input of resources to improve physical residential environments. Secondly, this study identifies the possible interactions between the physical and social factors in residential environments to better inform urban planning, which, in the past, has been mostly focused on improving physical aspects. By verifying the relationships between QoL and the physical and social factors in residential environments, the study results provide policy guidance for sustainable qualitative urban growth.

In the past, Korea has tended to only focus on quantitative growth, such as road and building construction, and has placed economic value as the priority [30]. Consequently, as Korea pursued its "rapid urbanization" without considering urban sustainability, similar to many other developing countries, many qualitative urban development problems were not addressed. However, Korea is now going through a transition period, and there has been an increased research focus on qualitative development [1,11]. Therefore, examining the QoL in Gyeonggi province, Korea, which is the most populous province in South Korea, could provide valuable urban management policy guidance for Korea and other developing countries.

\section{Materials and Methods}

\subsection{Study Area and Data}

This study area was Gyeonggi Province, Korea. Gyeonggi Province is adjacent to Seoul, the capital city of Korea, and consists of 31 districts (Figure 1). As of 2018, the population in Gyeonggi Province was 13,103,188, the largest population concentration in Korea, which made this province the most suitable for understanding the Korean QoL situation. To improve physical and social residential environments, Gyeonggi Province is currently promoting urban regeneration projects to increase resident QoL.

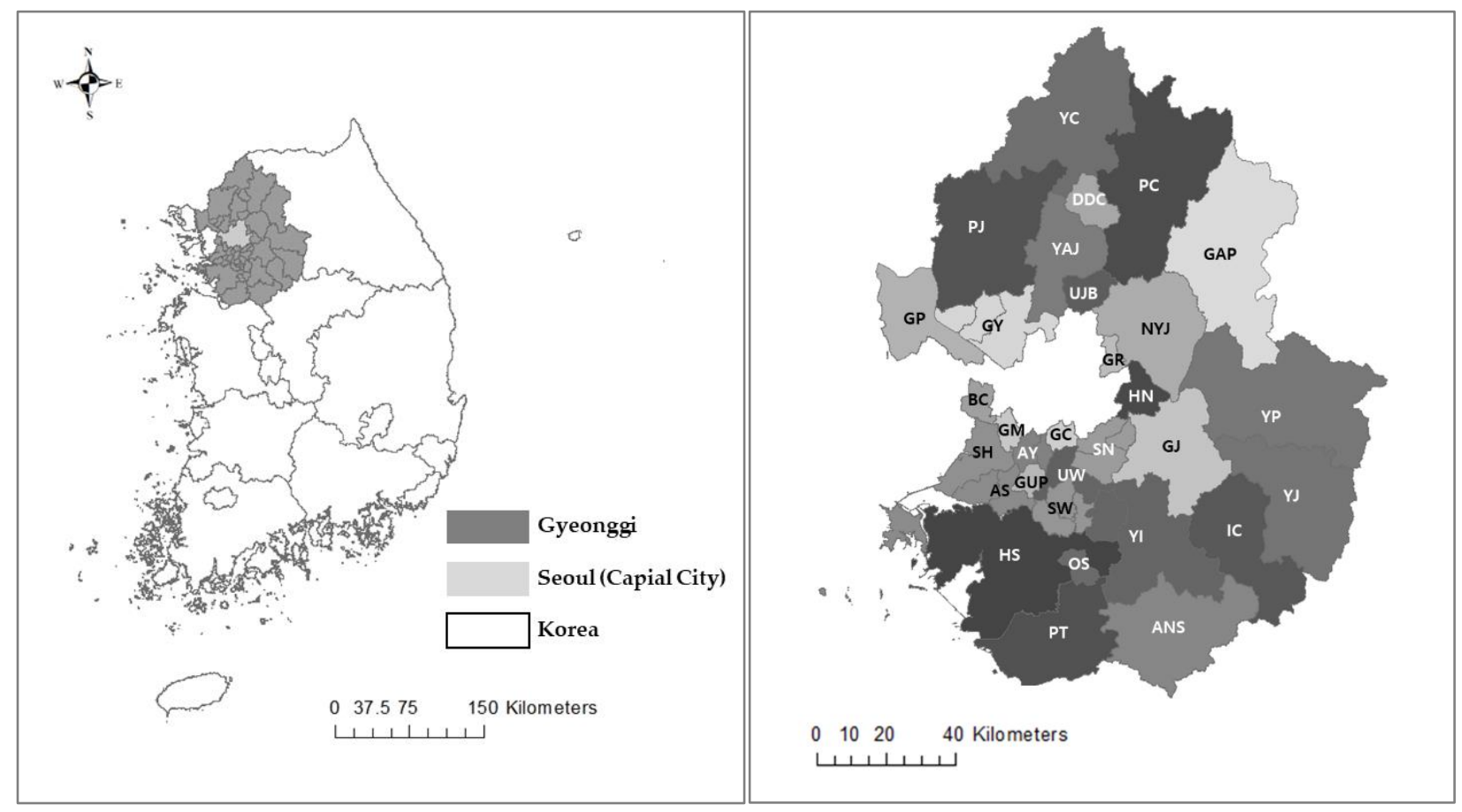

Figure 1. Study area: Gyeonggi Province in Korea. The 31 districts in Gyeonggi Province are Ansan(AS), Anseong(ANS), Anyang(AY), Bucheon(BC), Dongducheon(DDC), Gapyeong(GAP), Gimpo(GP), Goyang(GY), Gunpo(GUP), Guri(GR), Gwacheon(GC), Gwangju(GJ), Gwangmyeong(GM), Hanam(HN), Hwaseong(HS), Icheon(IC), Namyangju(NYJ), Osan(OS), Paju(PJ), Pocheon(PC), Pyeongtaek(PT), Seongnam(SN), Siheong(SH), Suwon(SW), Uijeongbu(UJB), Uiwang(UW), Yangju(YAJ), Yangpyeong(YP), Yeoju(YJ), Yongin(YI), and Yeoncheon(YC).

This study analyzed data from the QoL Survey that had been conducted on Gyeonggi Province residents by the Gyeonggi Research Institute. The survey collected data from 
20,000 households out of a total of 4.09 million households in Gyeonggi Province. Specifically, the sample design process was as follows. First, the population was divided into the 31 districts in Gyeonggi Province, and multistage stratified sampling was applied based on the number of household members and housing types (e.g., apartments, detached houses, multi-family houses, and row houses). Next, a minimum sample of 600 households was allocated for the representation of the sample by district. Finally, about $20 \%$ of samples were added for some districts with a relatively large population (e.g., Suwon, Yongin, Goyang, and Seongnam). The survey was conducted with face-to-face interviews using structured questionnaires [31]. Moreover, the survey included respondent demographics, such as sex, age, monthly household income, and housing tenure, as well as questions related to residential environment satisfaction and QoL. Therefore, the survey is appropriate for this study.

\subsection{Theoretical Analysis Framework}

This study focused on residential environments as an influence factor on QoL. Specifically, residential environments were divided into physical and social factors, and the effects of these factors on QoL were identified. In addition, this study verified the possibility of the moderating effect of the social factor between physical residential environment and QoL. Specific discussions are as follows.

\subsubsection{Relationship between Physical Environment Satisfaction and QoL}

This study considered the WHO's criteria [27] and constructed physical residential environment sub-components of facilities, commuting, and safety. Firstly, facilities satisfaction refers to satisfaction with the various facilities in a residential area. Some studies have shown that satisfaction with local facilities is related to a higher QoL [25,32,33]; that is, the higher the satisfaction with the various facilities is, the higher the QoL is. For example, De Vos and Witlox [34] found that the higher the satisfaction with commercial marts or medical facilities is, the higher the perceived QoL is. Next, commuting satisfaction refers to satisfaction with the transportation system convenience in residential areas, which is measured by the level of satisfaction with moving easily to other areas using public transportation such as buses and subways. Previous international and Korean studies have found that commuting satisfaction is an important factor in perceived QoL [35-37]. For example, Park and Kim [38] found that the transportation environment in residential areas was highly correlated with perceived resident QoL. Finally, safety satisfaction refers to satisfaction with safety in a residential area from disasters or accidents, and comprises a rapid response to accidents or disasters and well-established emergency medical systems. Previous studies have found that the safer a community is, the better the QoL is [39-41]. Based on these discussions, the following hypothesis is proposed.

Hypothesis 1 (H1). Satisfaction with the physical environmental factors of (a) facilities, (b) commuting, and (c) safety has a positive impact on QoL.

\subsubsection{Relationship between Neighborhood Satisfaction and QoL}

This study considers the social factor of residential environments as neighborhood satisfaction [5]. Neighborhood satisfaction is an emotional response to the neighborhood environment in a residential area [4]. Neighborhood satisfaction is related to the interactions with neighbors living in physically adjacent spaces. In many studies, neighborhood satisfaction has been identified as an important QoL factor [42-44]. For example, Cao [42] found that good relationships with neighbors could have a positive impact on QoL; Boessen et al. [45] found that low neighborhood satisfaction could negatively affect QoL; and in Korean studies, Kim [46] found that social capital based on neighborhood relationships could affect QoL. Therefore, the following hypothesis is proposed.

Hypothesis 2 (H2). Neighborhood satisfaction has a positive impact on QoL. 


\subsubsection{Moderating Effect of Neighborhood Satisfaction}

In addition to examining the effect of neighborhood satisfaction, this study also sought to verify the moderating effect of neighborhood satisfaction on QoL through the physical environmental factors. The moderating variable was validated by developing interaction terms with independent variables to assess the statistical significance on the dependent variable [47]. Few studies to date have dealt with the interactions between physical environmental factors and neighborhood satisfaction. However, some studies have found that physical environments were highly related to neighborhood satisfaction. For example, if neighborhood satisfaction was high, the satisfaction with convenience facilities, such as green parks and cafes, was also found to be high $[48,49]$, which could further strengthen the impact of physical environments on QoL. In addition, some studies on walkability have verified that physical factors such as safe walking environments were closely related to resident interactions [50,51]. Urban anchor facility planning was also found to be based on the relationship between the physical environment and neighborhood relations [52]. Lim and Lee [53] analyzed the impact of the physical environment on life satisfaction in middleaged people with social capital as a moderator and found that the lower the satisfaction with the physical environment is, the worse the negative life satisfaction is; however, if social capital based on neighborhood relations was well established, it partially offset this effect. These studies suggested that neighborhood satisfaction could be a moderator in the relationship between physical environment factors and QoL. Therefore, the following hypothesis is proposed, and the research model based on the above discussion is shown in Figure 2.

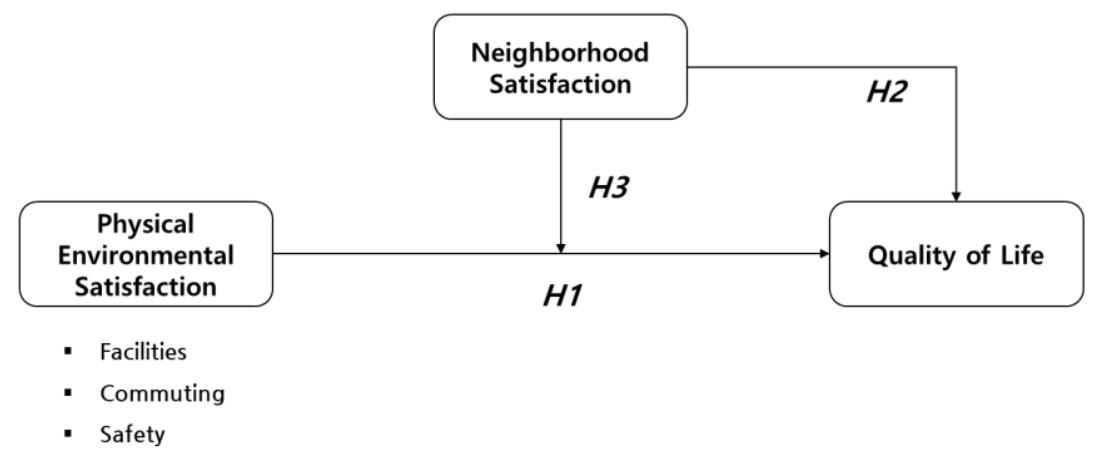

Figure 2. Research model.

Hypothesis 3 (H3). Neighborhood satisfaction moderates QoL through satisfaction with the physical residential environment factors of (a) facilities, (b) commuting, and (c) safety.

\subsection{Measures}

The main variables utilized in this study were as follows. First, QoL was taken as the dependent variable for the "overall life satisfaction" and "consistency of the ideal life" items, which were measured using a 5-point Likert scale of very dissatisfied (1), dissatisfied (2), neutral (3), satisfied (4), and very satisfied (5). Ko and Jeon [54] explained that QoL can be measured by short-term and long-term factors. Next, the physical environment factors were divided into facilities, commuting, and safety, which were measured using a 4-point Likert scale of very dissatisfied (1), dissatisfied (2), satisfied (3), and very satisfied (4). Satisfaction with the facilities comprised satisfaction with commercial facilities, medical institutions, public institutions, cultural facilities, green parks, and social welfare institutions. Park and Kim [38] also measured satisfaction with a number of facilities to evaluate the convenience of a community considering these kinds of facilities. However, survey items were measured through the overall level of satisfaction rather than specific criteria such as distance or size of facilities. That is, it is entirely based on individual perception. For example, some people may feel that a 10-min walk is far away, while others may feel the opposite. Satisfaction with commuting comprised satisfaction with "commuting with buses" and "commuting with 
subways". Buses and subways are representative public transportation systems. Wei [55] also evaluated a transportation system including these. Satisfaction with safety comprised satisfaction with perceptions of "safety from disasters or accidents", "rapidness of alert notifications in the event of disasters", and the "establishment of emergency medical system". Alerting of critical situations and emergency medical systems were cited as important factors in social risk perception [56]. Many studies dealing with neighborhood relationships or social capital utilized trust or interaction between residents as the main items $[25,57,58]$. This study also measured neighborhood satisfaction through these items. Finally, many studies have shown that demographic variables such as sex, age, monthly household income, and housing tenure affect QoL $[4,6,19]$. Therefore, this study also input these variables as control variables.

\subsection{Analytic Method}

The analysis was conducted using SPSS v21.0 and ArcGIS 10.8 based on the following procedures. First, an explanatory factor analysis (EFA) and reliability analysis were conducted to examine the internal validity of the measures. Second, the satisfaction with the factors was spatially compared by combining the respondents' residential areas with the survey results. This will help to understand the overall satisfaction level depending on the region. Third, descriptive and correlation analyses were conducted to determine the means, standard deviations, and correlations between the factors. Fourth, the moderating effect analysis recommended by Baron and Kenny [29] was performed for testing the hypotheses (Table 1) to analyze the effect of the independent and moderating variables on the dependent variable. Interaction terms for the independent and moderating variables were then added to determine their significance on the dependent variable based on the $\mathrm{R}^{2}$ and the $p$-value change in the F-value [47].

Table 1. Moderating effect analysis process.

\begin{tabular}{ccc}
\hline Step & Regression Equations & Conditions \\
\hline Step 1 & $\mathrm{Y}=\mathrm{B} 10+\mathrm{B} 11 \mathrm{X}+\mathrm{B} 12 \mathrm{M}$ & \\
\hline Step 2 & $\mathrm{Y}=\mathrm{B} 20+\mathrm{B} 21 \mathrm{X}+\mathrm{B} 22 \mathrm{M}+\mathrm{B} 23 \mathrm{XM}$ & $\Delta \mathrm{R}^{2}$ should increase significantly. \\
\hline
\end{tabular}

Note: $\mathrm{B}$ is a regression coefficient, $\mathrm{X}$ is an independent variable, $\mathrm{M}$ is a moderating variable, and $\mathrm{XM}$ is an interaction term.

\section{Results}

\subsection{Exploratory Factor Analysis (EFA) and Reliability Analysis}

An EFA and reliability analysis were conducted to verify the validity and reliability of the measurements (Table 2). The EFA generated five factors from the 16 items, each of which was found to be greater than 0.6 and have eigenvalues higher than 1 , which indicated that the measurements' abilities to explain each factor were reasonable. Cronbach's $\alpha$ of 0.6 or greater was also considered acceptable [47], with all factors being higher than 0.6.

\subsection{Spatial Comparison for Factors}

This study presents the satisfaction level with factors depending on the residential area (Figure 3). The specific results are as follows. Physical environment satisfaction and neighborhood satisfaction were spatially different. For example, the closer an area is to Seoul, the higher the overall physical environment satisfaction is. Lee and Park [59] explained that the closer the adjacent areas are to Seoul, the higher the residential environment satisfaction is. On the other hand, neighborhood satisfaction was relatively high in areas far from Seoul. Neighborhood satisfaction has been verified as being high in areas with a low population density [60]. These areas have a relatively low population density. Finally, the QoL was found to be higher in the southern region than in the northern region based over Seoul. The northern region of Gyeonggi Province is restricted from urban development due to its military zone with North Korea. Therefore, these regions showed a lower QoL for residents 
as well as facility infrastructure compared to the southern region of Gyeonggi Province [61]. Meanwhile, QoL tends to be spatially similar to satisfaction with facilities or safety.

Table 2. Exploratory factor analysis (EFA) and reliability analysis.

\begin{tabular}{|c|c|c|c|c|}
\hline Cate & & Measurement & Factor Loading & $\begin{array}{l}\text { Eigenvalue } \\
\text { /Cronbach } \alpha\end{array}$ \\
\hline \multirow{11}{*}{$\begin{array}{l}\text { Physical environment } \\
\text { satisfaction }\end{array}$} & \multirow{6}{*}{ Facilities } & Satisfaction with commercial facilities & 0.646 & \multirow{6}{*}{$\begin{array}{l}2.850 \\
/ 0.776\end{array}$} \\
\hline & & Satisfaction with medical institutions & 0.659 & \\
\hline & & Satisfaction with public institutions & 0.678 & \\
\hline & & Satisfaction with cultural facilities & 0.677 & \\
\hline & & Satisfaction with green parks & 0.705 & \\
\hline & & Satisfaction with social welfare institutions & 0.690 & \\
\hline & \multirow{2}{*}{ Commuting } & Commuting with buses & 0.826 & \multirow{2}{*}{$\begin{array}{l}1.514 \\
/ 0.677\end{array}$} \\
\hline & & Commuting with subways & 0.848 & \\
\hline & \multirow{3}{*}{ Safety } & Safety from disasters and accidents & 0.634 & \multirow{3}{*}{$\begin{array}{l}1.799 \\
/ 0.641\end{array}$} \\
\hline & & Rapidness of alert notifications on disasters & 0.799 & \\
\hline & & Establishment of emergency medical system & 0.763 & \\
\hline \multirow{3}{*}{\multicolumn{2}{|c|}{$\begin{array}{l}\text { Neighborhood } \\
\text { satisfaction }\end{array}$}} & Helping residents well & 0.904 & \multirow{3}{*}{$\begin{array}{l}2.304 \\
/ 0.845\end{array}$} \\
\hline & & Getting help from residents & 0.898 & \\
\hline & & Trust in residents & 0.803 & \\
\hline \multirow{2}{*}{\multicolumn{2}{|c|}{ Quality of life }} & Overall life satisfaction & 0.892 & 1.649 \\
\hline & & Consistency with an ideal life & 0.886 & $/ 0.800$ \\
\hline
\end{tabular}

$\mathrm{KMO}=0.778$, Bartlett sphericity test $=0.000$.

\subsection{Descriptive and Correlation Analyses}

Table 3 shows the results for the descriptive and correlation analyses between the factors. First, the facilities satisfaction was the highest of the physical environment subcomponents at 2.91 (4-point scale) and commuting was the lowest at 2.63. Neighborhood satisfaction was 2.59, which was lower than all of the physical environment subcomponents, which indicates that neighborhood satisfaction improvements are urgently needed. Finally, QoL was 3.39 (5-point scale), which is considered normal.

A Pearson correlation analysis between the factors was also conducted, from which it was found that all factors had significant positive correlations at the $99 \%$ confidence level. Specifically, QoL was verified to correlate relatively strongly with facilities and safety satisfaction. This is consistent with the earlier spatial comparison (Figure 3). On the other hand, as a correlation coefficient of 0.7 or higher indicates possible multicollinearity in regression analyses [47], this was also assessed, but because the correlation coefficient was found to be less than 0.4 for all factors, there was no evidence of multicollinearity.

\subsection{Moderating Effect Analysis}

This study sought to verify the influence of satisfaction with physical and social environment factors on QoL and assess the moderating effect of neighborhood satisfaction between the two. Therefore, the moderating effect analysis recommended by Baron and Kenny [29] (Table 4) was conducted. Prior to the analysis, the model fit for all steps and the $p$-value for $\Delta \mathrm{F}$ were found to be statistically significant. The explanatory power was measured as $15.3 \%\left(R^{2}=0.153\right)$ based on Step 2, which included all variables.

The specific moderating effect analysis results were as follows. Step 1 confirmed that satisfaction with the facilities, commuting, and safety physical environment subcomponents had a positive effect on QoL, and based on the standard coefficient, the satisfaction with facilities $(\beta=0.151$ ) had a relatively strong influence and neighborhood satisfaction positively affected QoL. In Step 2, additional interaction terms were input between the independent variables and the moderator, from which it was found that satisfaction with all physical environment sub-components and neighborhood relations had a positive effect on QoL. Of the interaction terms, "safety * neighborhood satisfaction" was found to have a positive effect, which indicated that neighborhood satisfaction moderated the relationship between satisfaction with safety and QoL. The sex, age, monthly household 
income, and housing tenure control variables were also all found to have a significant impact on QoL.

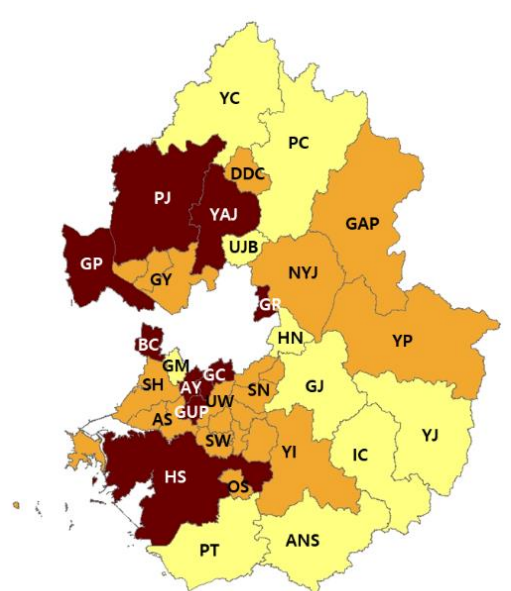

(a)

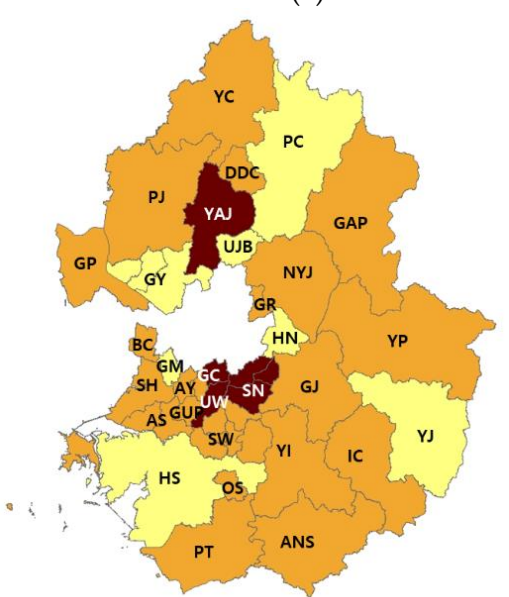

(c)

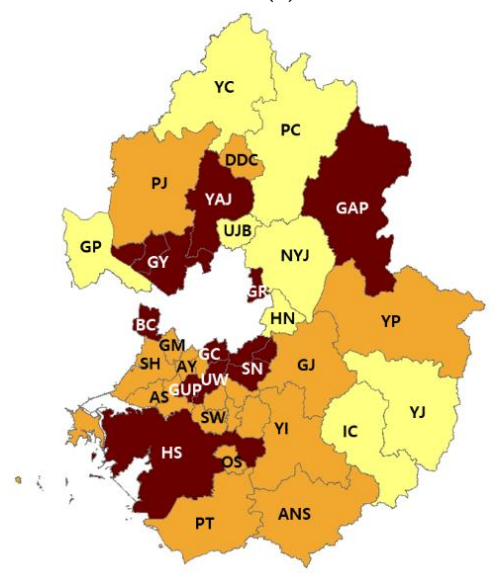

(e)

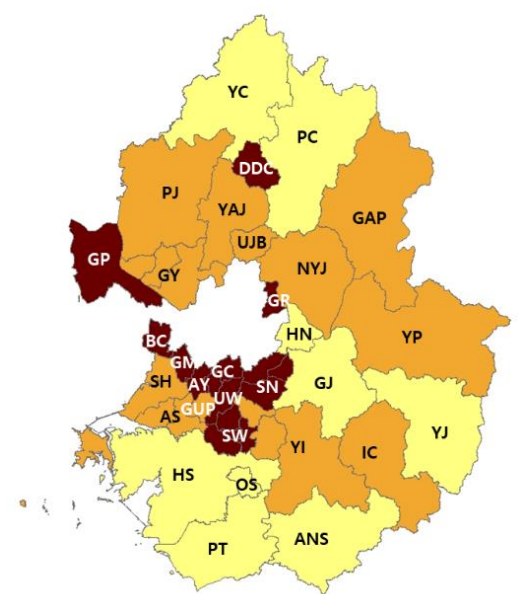

(b)

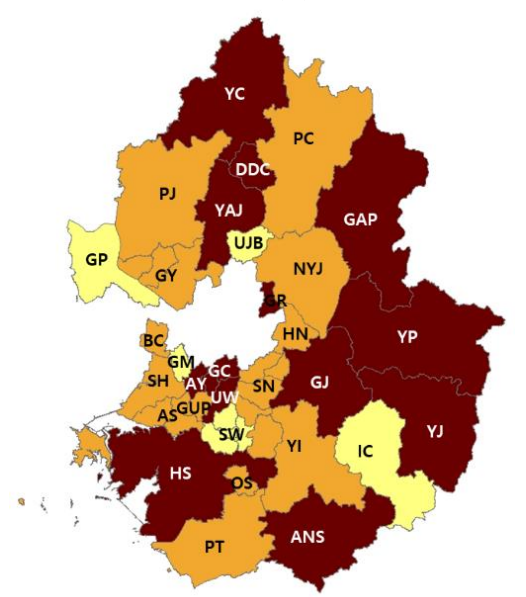

(d)
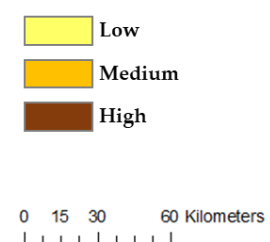

Figure 3. Spatial comparison for factors. (a) Facilities satisfaction; (b) Commuting satisfaction; (c) Safety satisfaction; (d) Neighborhood satisfaction; (e) Quality of life. Note: AS; Ansan, ANS; Anseong, AY; Anyang, BC; Bucheon, DDC; Dongducheon, GAP; Gapyeong, GP; Gimpo, GY; Goyang, GUP; Gunpo, GR; Guri, GC; Gwacheon, GJ; Gwangju, GM; Gwangmyeong, HN; Hanam, HS; Hwaseong, IC; Icheon, NYJ; Namyangju, OS; Osan, PJ; Paju, PC; Pocheon, PT; Pyeongtaek, SN; Seongnam, SH; Siheong, SW; Suwon, UJB; Uijeongbu, UW; Uiwang, YAJ; Yangju, YP; Yangpyeong, YJ; Yeoju, YI; Yongin, YC; Yeoncheon. 
Table 3. Descriptive statistics and correlations between factors.

\begin{tabular}{ccccccccc}
\hline & Variable & Mean & Std. Dev. & $\mathbf{1}$ & $\mathbf{2}$ & $\mathbf{3}$ & $\mathbf{4}$ & $\mathbf{5}$ \\
\hline 1 & Facilities & 2.91 & \pm 0.461 & 1 & & & & \\
2 & Commuting & 2.63 & \pm 0.651 & $0.284^{* *}$ & 1 & & \\
3 & Safety & 2.73 & \pm 0.528 & $0.290^{* *}$ & $0.308^{* *}$ & 1 & \\
4 & Neighborhood satisfaction & 2.59 & \pm 0.693 & $0.039^{* *}$ & $0.032^{* *}$ & $0.164^{* *}$ & 1 & \\
5 & Quality of life & 3.39 & \pm 0.679 & $0.236^{* *}$ & $0.167^{* *}$ & $0.227^{* *}$ & $0.180^{* *}$ & 1 \\
\hline
\end{tabular}

Note. Quality of life: 5-point scale; Others: 4-point scale. ${ }^{* *} p<0.01$.

Table 4. Moderating effect analysis.

\begin{tabular}{|c|c|c|c|c|c|}
\hline & & \multicolumn{2}{|c|}{ Step 1} & \multicolumn{2}{|c|}{ Step 2} \\
\hline & & B (S.E) & $\beta$ & B (S.E) & $\beta$ \\
\hline \multirow{4}{*}{ Control variables } & Sex (ref. male) & $0.075(0.012)$ & $0.040 * *$ & $0.076(0.012)$ & $0.040 * *$ \\
\hline & Age & $-0.003(0.000)$ & $-0.056^{* *}$ & $-0.003(0.000)$ & $-0.056^{* *}$ \\
\hline & Monthly household income & $0.001(0.000)$ & $0.170^{* *}$ & $0.001(0.000)$ & $0.170^{* *}$ \\
\hline & Housing tenure (ref. renters) & $0.101(0.011)$ & $0.073 * *$ & $0.103(0.011)$ & $0.074^{* *}$ \\
\hline \multirow{3}{*}{$\begin{array}{l}\text { Physical environment } \\
\text { satisfaction }\end{array}$} & Facilities $(a)$ & $0.223(0.010)$ & $0.151^{* *}$ & $0.223(0.010)$ & $0.152 * *$ \\
\hline & Commuting $(b)$ & $0.073(0.007)$ & $0.070 * *$ & $0.071(0.007)$ & $0.068^{* *}$ \\
\hline & Safety $(c)$ & $0.162(0.009)$ & $0.126^{* *}$ & $0.161(0.009)$ & $0.125^{* *}$ \\
\hline \multicolumn{2}{|c|}{ Neighborhood satisfaction $(d)$} & $0.151(0.007)$ & $0.154^{* *}$ & $0.149(0.007)$ & $0.152 * *$ \\
\hline \multirow{3}{*}{$\begin{array}{l}\text { Interaction } \\
\text { terms }\end{array}$} & $(a) *(d)$ & & & $0.003(0.015)$ & 0.002 \\
\hline & $(b) *(d)$ & & & $0.005(0.010)$ & 0.003 \\
\hline & $(c) *(d)$ & & & $0.044(0.012)$ & $0.025^{* *}$ \\
\hline Constant & & $1.330(0.045)$ & - & $1.335(0.045)$ & - \\
\hline \multicolumn{2}{|r|}{$n$} & \multicolumn{2}{|c|}{20,000} & \multicolumn{2}{|c|}{20,000} \\
\hline \multicolumn{2}{|c|}{ F-value } & \multicolumn{2}{|c|}{$483.088^{* *}$} & \multicolumn{2}{|c|}{$6.596 * *$} \\
\hline \multicolumn{2}{|c|}{$p$-value for $\Delta \mathrm{F}$} & \multicolumn{2}{|c|}{0.000} & \multicolumn{2}{|c|}{0.001} \\
\hline \multicolumn{2}{|r|}{$\mathrm{R}^{2}$} & \multicolumn{2}{|c|}{0.152} & \multicolumn{2}{|c|}{0.153} \\
\hline
\end{tabular}

Note. It may seem that $\Delta \mathrm{R}^{2}$ does not differ significantly between the models. However, its significance was determined by considering the number of samples together in the statistical package (e.g., SPSS). ${ }^{* *} p<0.01$.

\section{Discussion}

The study results have several implications for the relationships between physical environment satisfaction, neighborhood satisfaction, and QoL.

Firstly, all physical environment satisfaction sub-components were found to have a positive effect on QoL, which confirmed Hypothesis 1 and was in agreement with the results in many previous studies that found that the higher the physical environment satisfaction is, the higher the QoL is [25,34-36]. In particular, it was shown that the satisfaction with facilities had the greatest influence on QoL. Biagi et al. [62] found that various facilities in the residential area were highly related to convenience and were directly related to residential QoL. Therefore, the establishment of commercial, medical, and public institution facilities in communities needs to be prioritized to improve QoL [25] As mentioned, since residents tend to primarily meet their needs within their immediate communities [21], convenient physical environments could satisfy these needs and lead to improved residential QoL. For example, Park and Lee [63] found that the convenience of local facilities was relatively important when people were choosing housing in metropolitan areas such as Gyeonggi. Therefore, it is necessary to pay attention to improving the facilities in residential areas when seeking to increase QoL, which means that local governments need to focus on providing the facilities and infrastructure needed by local residents as well as ensuring that the current facilities are convenient to use. In particular, the northern districts, where QoL was low relatively, will require more efforts to increase satisfaction with facilities. 
Secondly, neighborhood satisfaction was found to have a positive effect on QoL, which confirmed Hypothesis 2; that is, the social factor in residential environments is important to QoL. Previous studies have also verified that social capital based on neighborhood relationships is an important factor affecting life satisfaction [42-45]. This finding is significant as past urban management paradigms have been mainly focused on physical aspects (e.g., roads and building construction). The descriptive statistical analysis (Table 3) also showed that neighborhood satisfaction is lower than all physical environment satisfaction subcomponents. However, as social satisfaction based on neighborhood relations is now being emphasized in recent urban regeneration efforts, the results of this study have important theoretical implications. Therefore, various local events such as local markets should be arranged to allow residents to interact and other resident community activities need to be supported (e.g., social gatherings between residents).

Thirdly, "safety * neighborhood satisfaction" was proven to have a positive effect on QoL, indicating that neighborhood satisfaction moderated the relationship between safety satisfaction and QoL. More specifically, if neighborhood satisfaction is high, the influence of safety on QoL could be further strengthened. The graphical analysis in Figure 4 clearly illustrates that the relationship between safety and QoL differs depending on the level of neighborhood satisfaction. As the level of neighborhood satisfaction increases, the slope of the graph gradually increases, indicating that the influence of safety on QoL increases. Some studies have also found a high correlation between physical environment and neighborhood relations $[48,49,52,53]$. Due to the spread of infectious diseases such as COVID-19 and MERS in communities, there has been an increase in the distrust between local residents and a drop in community safety satisfaction, which also supports the findings of this study that improving neighborhood interactions can increase safety satisfaction and thus improve QoL.

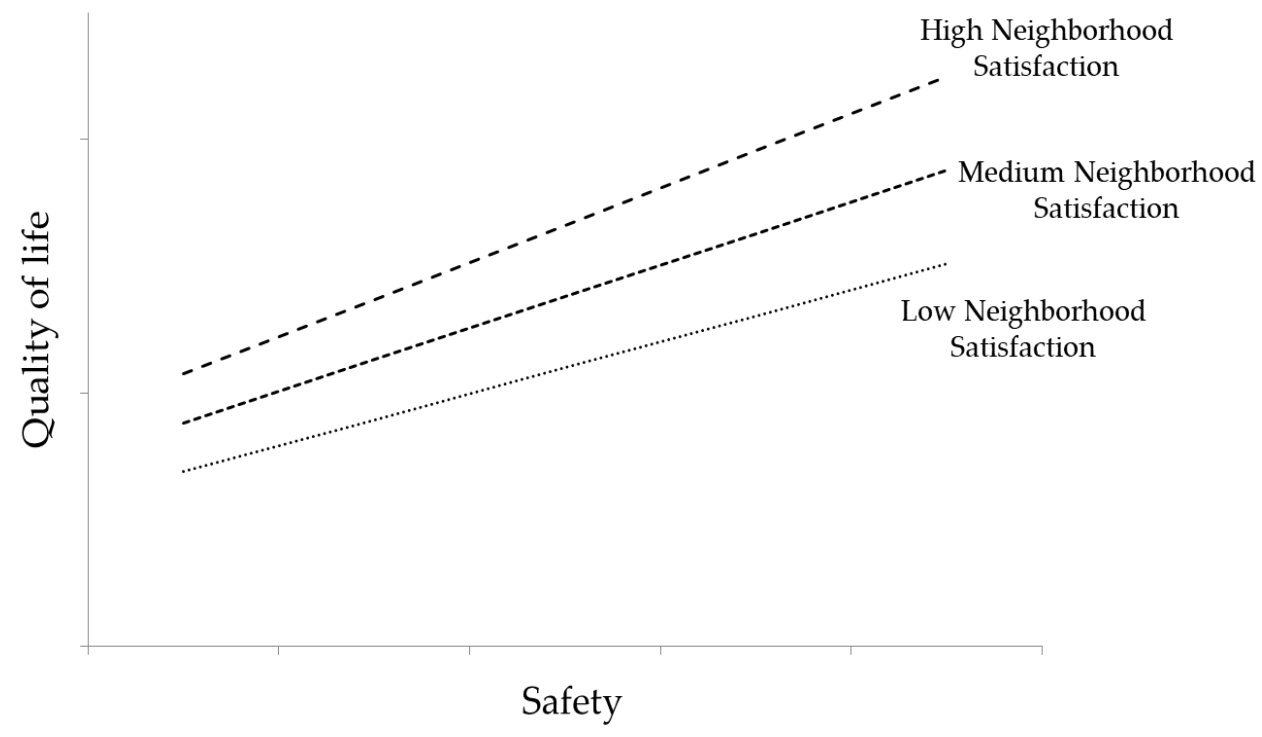

Figure 4. Moderating effect of neighborhood satisfaction on safety and QoL.

\section{Conclusions}

Previous studies on QoL have tended to focus on economic factors and neglected the importance of residential environments. However, the QoL for residents may vary depending on the satisfaction with the residential environment. Therefore, this study examined the relationships between physical environment satisfaction, neighborhood satisfaction, and QoL based on an analysis of the Quality of Life Survey data from Gyeonggi Province, Korea. Specifically, the physical environment satisfaction was divided into satisfaction with facilities, commuting, and safety, and the effect of these each factors and neighborhood satisfaction on quality of life was verified, and the moderating effect of neighbor satisfaction was also assessed. 
Based on the findings, this study contributes the following to research knowledge on QoL. First, this study distinguished various sub-factors of residential environments and verified the priorities among them. This provides important implications regarding which aspects should be focused on in the residential environment improvement project for QoL. In particular, considering the limited budget for individual projects, the importance of deriving priorities is further increased. Second, the social factor in residential environments was verified in various aspects; that is, neighborhood satisfaction was found to directly affect QoL and to strengthen the impact of the physical factor of safety on QoL. In general, improving the physical aspect of residential environments is costly, but not increasing neighborhood satisfaction. Therefore, increasing neighborhood satisfaction will be more efficient in improving QoL.

Since the mid-1980s, "low growth" has been experienced in several countries such as Korea and Japan, which means that there has been commensurate low quantitative urban development growth [12]. Therefore, there has been a change in the focus in urban development paradigms, with qualitative growth being recognized as necessary to ensure urban sustainability $[10,11]$. Korea experienced rapid growth in the past but has had a sluggish economy for several decades; therefore, today, major cities in Korea are attempting to change their urban policies to deal with this low-growth era [23]. In particular, it was found that both physical and social residential environment factors played an important role in improving perceived QoL, which suggests that developing countries need to have integrated physical and social factor policy approaches rather than only pursuing urban growth based on physical aspects.

Regardless of these positive results, this study has several limitations. Firstly, it only considered facilities, commuting, and safety as the physical residential environment factors; therefore, future studies need to verify the presence of other possible factors. Secondly, this study only focused on Gyeonggi; therefore, more meaningful conclusions could be made if such studies were expanded and comparative studies were conducted based on regional characteristics. Finally, some researchers evaluate the conversion of the area of housing per capita to assess QoL. However, the survey data in this study are based on a single year. Therefore, there has been a lack of consideration for this.

Funding: This research received no external funding.

Institutional Review Board Statement: Not applicable.

Informed Consent Statement: Not applicable.

Data Availability Statement: Restrictions apply to the availability of these data. Data were obtained from the Gyeonggi Research Institute and are available from the author with the permission of the Gyeonggi Research Institute.

Acknowledgments: The authors want to thank the editors and the reviewers for their constructive comments that helped improve the current paper.

Conflicts of Interest: The author declares no conflict of interest.

\section{References}

1. Friedmann, J.; Alonso, W. Regional Policy; Readings in Theory and Applications; The MIT Press: Cambridge, MA, USA, 1975.

2. Song, J.Y.; Yim, S.K. Theoretical exploration of social sustainability for the qualitative development of cities. J. Korean Geogr. Soc. 2015, 50, 677-694.

3. OECD. How's Life? 2020: Measuring Well-Being; OECD Better Life Initiative: Paris, France, 2020.

4. Mouratidis, K. Commute satisfaction, neighborhood satisfaction, and housing satisfaction as predictors of subjective well-being and indicators of urban livability. Travel Behav. Soc. 2020, 21, 265-278. [CrossRef]

5. OECD. OECD Guidelines on Measuring Subjective Well-Being; OECD Better Life Initiative: Paris, France, 2013.

6. Sirgy, M.J.; Gao, T.; Young, R. How does residents' satisfaction with community services influence quality of life (QOL) outcomes? Appl. Res. Qual. Life 2008, 3, 81-105. [CrossRef]

7. Veenhoven, R. Happiness: Also known as "life satisfaction" and "subjective well-being". In Handbook of Social Indicators and Quality of Life Research; Land, K., Michalos, A., Sirgy, M., Eds.; Springer Publishing: New York, NY, USA, 2012 ; pp. 63-77. [CrossRef] 
8. Dunning, H.; Williams, A.; Abonyi, S.; Crooks, V. A mixed method approach to quality of life research: A case study approach. Soc. Indic. Res. 2008, 85, 145-158. [CrossRef]

9. Rezvani, M.R.; Mansourian, H.; Sattari, M.H. Evaluating quality of life in urban areas (case study: Noorabad City, Iran). Soc. Indic. Res. 2013, 112, 203-220. [CrossRef]

10. Friedmann, J. The good city: In defense of utopian thinking. Int. J. Urban Reg. Res. 2000, 24, 460-472. [CrossRef]

11. Kelly, J.F.; Breadon, P.; Davis, C.; Hunter, A.; Mares, P.; Weidmann, B. Social Cities; Grattan Institute: Carlton, Australia, 2012.

12. Cho, M.R. The Low Growth and Change of Urban Paradigm, New Urban Policies in the Low Growth Era; Hanul Publishing: Gyeonggi, Korea, 2011.

13. Deaton, A. Income, health, and well-being around the world: Evidence from the Gallup World Poll. J. Econ. Perspect. 2008, 22, 53-72. [CrossRef] [PubMed]

14. Sacks, D.W.; Stevenson, B.; Wolfers, J. Subjective well-being, income, economic development and growth. NBER Work Pap. 2010, 16441. [CrossRef]

15. Stevenson, B.; Wolfers, J. Subjective well-being and income: Is there any evidence of satiation? Am. Econ. Rev. 2013, 103, 598-604. [CrossRef]

16. Lim, G.S. Recognition of local residents on quality of life and its influencing factors: Focused on the cities and counties in gangwon province. Korean Public Adm. Policy 2012, 6, 47-89.

17. Lee, K.Y.; Jeong, J.H.; Jun, H.J. The effect of regional disparity and housing characteristics of Seoul's Gangnam and Gangbuk Districts on the social-class recognition: Focusing on low-income class recognition. J. Korean Urban Manag. Assoc. 2018, 31, 77-100. [CrossRef]

18. Altman, I.; Low, S.M. Place Attachment; Plenum Press: New York, NY, USA, 1992.

19. Moreno-Jiménez, M.P.; Vallejo, M.; Rios, M.L. Improving quality of life via social work: Influence of residential and community variables on life satisfaction. Int. Soc. Work 2016, 60, 1564-1577. [CrossRef]

20. Brehm, J.M.; Eisenhauer, B.W.; Krannich, R.S. Community attachments as predictors of local environmental concern: The case for multiple dimensions of attachment. Am. Behav. Sci. 2006, 50, 142-165. [CrossRef]

21. Lee, H.C.; Park, H.B.; Jung, W.L. An analysis on the factors to affect the settlement consciousness of in habitants. Korean Assoc. Policy Stud. 2004, 13, 147-167.

22. Lewicka, M. Place attachment: How far have we come in the last 40 years? J. Environ. Psychol. 2011, 31, 207-230. [CrossRef]

23. Ministry of Land, Infrastructure and Transport. Guideline for Urban Regeneration New-Deal Projects; Ministry of Land, Infrastructure and Transport: Sejong, Korea, 2018.

24. Bae, W.K.; Kim, U.H.; Lee, J.W. Evaluation of the criteria for designating maintenance districts in low-rise residential areas: Urban renewal projects in Seoul. Sustainability 2019, 11, 5876. [CrossRef]

25. Özkan, D.G.; Yilmaz, S. The effects of physical and social attributes of place on place attachment: A case study on Trabzon urban squares. Archnet IJAR 2019, 13, 133-150. [CrossRef]

26. Salama, A.M.; Remali, A.M.; MacLean, L. Characterisation and systematic assessment of urban open spaces in Glasgow city centre. Spatium 2017, 37, 22-33. [CrossRef]

27. WHO. Expert Committee on the Public Health Aspects of Housing, 19-26 June 1961; WHO: Geneva, Switzerland, 1961.

28. Lee, K.Y. A study on the factors affecting the place attachment: Focusing on the moderating effect of social capital. J. Korean Urban Manag. Assoc. 2019, 32, 1-20. [CrossRef]

29. Baron, R.M.; Kenny, D.A. The moderator-mediator variable distinction in social psychological research: Conceptual, strategic, and statistical considerations. J. Abnorm. Soc. Psychol. 1986, 51, 1173-1182. [CrossRef]

30. Joo, Y.M. Megacity Seoul: Urbanization and the Development of Modern South. Korea; Routledge: Abingdon-on-Thames, UK, 2020.

31. Lee, B.H.; Son, W.B. Designing a longitudinal survey for measuring the quality of life. GRI Rev. 2017, 36, 1-24.

32. Fornara, F.; Manca, S. Healthy residential environments for the elderly. In International Handbooks of Quality-of-Life; Fleury-Bahi, G., Pol, E., Navarro, O., Eds.; Springer Publishing: New York, NY, USA, 2016; pp. 441-465. [CrossRef]

33. Kuijlenburg, R. Teaching urban facility management, global citizenship and livability. Facilities 2020, 38, 849-857. [CrossRef]

34. De Vos, J.; Witlox, F. Travel satisfaction revisited. On the pivotal role of travel satisfaction in conceptualising a travel behaviour process. Trans. Res. Part A Policy. Prac. 2017, 106, 364-373. [CrossRef]

35. Ahmadiani, M.; Ferreira, S. Environmental amenities and quality of life across the United States. Ecol. Econ. 2019, 164, 106341. [CrossRef]

36. Gao, Y.; Rasouli, S.; Timmermans, H.; Wang, Y. Understanding the relationship between travel satisfaction and subjective well-being considering the role of personality traits: A structural equation model. Transport. Res. Part F Traffic Psychol. Behav. 2017, 49, 110-123. [CrossRef]

37. Olsson, L.E.; Gärling, T.; Ettema, D.; Friman, M.; Fujii, S. Happiness and satisfaction with work commute. Soc. Indic. Res. 2015, 111, 255-263. [CrossRef]

38. Park, J.A.; Kim, B.S. Influence of residents attachment to the community on participation in community-building activities: Focusing on Hannam 1 dong. J. Urban Des. Inst. Korea Urban Des. 2014, 15, 215-226.

39. Ibem, E.O.; Aduwo, E.B. Assessment of residential satisfaction in public housing in Ogun State, Nigeria. Habitat Int. 2013, 40, 163-175. [CrossRef] 
40. Marans, R.; Robert, J.S. Investigating Quality of Urban Life Theory, Methods, and Empirical Research; Springer Publishing: New York, NY, USA, 2011.

41. Martínez, L.; Short, J.; Ortíz, M. Citizen satisfaction with public goods and government services in the global urban south: A case study of Cali, Colombia. Habitat Int. 2015, 49, 84-91. [CrossRef]

42. Cao, X. How does neighborhood design affect life satisfaction? Evidence from Twin Cities. Travel Behav. Soc. 2016, 5, 68-76. [CrossRef]

43. Lee, S.M.; Conway, T.L.; Frank, L.D.; Saelens, B.E.; Cain, K.L.; Sallis, J.F. The relation of perceived and objective environment attributes to neighborhood satisfaction. Environ. Behav. 2017, 49, 136-160. [CrossRef]

44. Mouratidis, K. Built environment and social well-being: How does urban form affect social life and personal relationships? Cities 2018, 74, 7-20. [CrossRef]

45. Bossen, A.; Hipp, J.R.; Butt, C.T.; Nagle, N. The built environment, Spatial scale, and social networks: Do land uses matter for personal network structure? Environ. Plan B Urban Anal. City Sci. 2017, 45, 400-416. [CrossRef]

46. Kim, H.Y. Study on the Effects of Social Capital on Subjective well-being. J. Korean Soc. Welf. Adm. 2020, 22, 41-68.

47. Lee, H.S.; Lim, J.H. SPSS 24 Manual; JypHyunJae Publishing Co.: Seoul, Korea, 2017.

48. Frank, L.; Kerr, J.; Rosenberg, D.; King, A. Health aging and where you live: Community design relationship with physical activity and body weight in older Americans. J. Phys. Act. Health 2010, 7, S82-S90. [CrossRef]

49. Hong, A.; Sallis, J.F.; King, A.C.; Conway, T.L.; Saelens, B.; Cain, K.L.; Fox, E.H.; Frank, L.D. Linking green space to neighborhood social capital in older adults: The role of perceived safety. Soc. Sci. Med. 2018, 207, 38-45. [CrossRef]

50. Jun, H.; Hur, M. The relationship between walkability and neighborhood social environment: The importance of physical and perceived walkability. Appl. Geogr. 2015, 62, 115-124. [CrossRef]

51. Lund, H. Pedestrian environments and sense of community. J. Plan. Educ. Res. 2002, 21, 301-312. [CrossRef]

52. Seifried, C.; Clopton, A.W. An alternative view of public subsidy and sport facilities through social anchor theory. City Cult. Soc. 2013, 4, 49-55. [CrossRef]

53. Lim, S.M.; Lee, B.Y. Effects of residential environment on life satisfaction among the middle-aged: Focused on the moderating effects of social capital. Asia Pac. J. Bus. Ventur. Entrep. 2016, 11, 49-63.

54. Ko, E.J.; Jeon, S.B. The Quality of life and commuting: Considering time use and income of kyunggi resident. GRI Rev. 2017, 36, 25-50.

55. Wei, W.M. Constructing urban dynamic transportation planning strategies for improving quality of life and urban sustainability under emerging growth management principles. Sustain. Cities Soc. 2019, 44, 275-290. [CrossRef]

56. Chung, J.B.; Lyu, H.S. The Korean Public's Social Risk Perception and Its Policy Implications; The Korea Institute of Public Administration: Seoul, Korea, 2009.

57. Kamalipour, H.; Yeganeh, A.J.; Alalhesabi, M. Predictors of place attachment in urban residential environments: A residential complex case study. Procedia Soc. Behav. Sci. 2012, 35, 459-467. [CrossRef]

58. Lee, K.Y. Residential environmental satisfaction, social capital, and place attachment: The case of Seoul, Korea. J. Hous. Built Environ. 2021, 36, 559-575. [CrossRef]

59. Lee, H.C.; Park, H.B. An analysis on the disparities of development levels among the local governments in Gyeonggi Province. Korean Public Adm. Rev. 2006, 40, 327-351.

60. Jang, H.D. An analysis of factors influencing residential satisfaction according to population sizes and locations of cities. J. Resid. Environ. Inst. Korea 2020, 18, 23-46. [CrossRef]

61. Jang, Y.H. The policy implications and characteristics of regional disparities and urban area gaps: The case of 31 counties in Gyeonggi Province. Korea Local Adm. Rev. 2015, 29, 99-125.

62. Biagi, B.; Ladu, M.G.; Meleddu, M. Urban quality of life and capabilities: An experimental study. Ecol. Econ. 2018, 150, 137-152. [CrossRef]

63. Park, K.J.; Lee, S.W. Determinants of housing expenditure in Seoul Metropolitan area, 2006-2014: Application of multi-level model. Korea Spat. Plan. Rev. 2015, 87,33-48. 